\title{
OBSERVANDO AS NARRATIVAS DAS CRIANÇAS EM SUAS PERFORMANCES DE PARTICIPAÇÃO LÚDICAS MEDIADAS PELA MUSICALIZAÇÃO
}

\author{
AUTOR: NATALIA PEREIRA DE OLIVEIRA
}

CO-AUTOR/ORIENTADOR: MARINA RODRIGUES MIRANDA

Resumo: Trata-se de estudo de abordagem qualitativa realizado a partir de revisão bibliográfica ensejando analisar as potencialidades da música e da ludicidade como mecanismos estimuladores da partilha de narrativas vivas de crianças e adolescentes que exercitam suas infâncias e juventudes em tratamento oncológico. Constatou-se, mediante a literatura consultada, que, compor pesquisas usando dispositivos musicais e atividades lúdicas estimula as crianças e pode auxiliá-las a lidar com a patologia e a hospitalização. No percurso do trabalho etnográfico percebemos nas vivências realizadas com as crianças assistidas pela $\mathrm{ACACCl}$, que elas externalizaram sentimentos e criaram mecanismos para enfrentarem o processo de adoecimento e as problemáticas envolvidas oriundas do duro tratamento. Os referenciais teóricos acessados em estudos são fundantes para a composição de análises das transcrições das escritas etnográficas. Para esta composição, revisitamos também os artigos e as experiências que foram produzidas pelo NUPEEES para congressos, e oficinas que foram realizadas com profissionais da área de saúde e Educação. Conclui-se que a produção constituída a partir do movimento da pesquisa deste campo de estudo reafirma que as crianças preservam suas autonomias e, como sujeitos encarnados, expressam na corporeidade narrativas vivas, que corroboram para o equilíbrio das energias vitais, primordiais para o processo de reintegração da saúde.

Palavras-chave: Infância, oncologia, música, ludicidade. 